\title{
Violence in the "Balance": A Structural Analysis of How Rivals, Allies, and Third-Parties Shape Inter-Gang Violence
}

\author{
Kiminori Nakamura \\ University of Maryland \\ George Tita \\ University of California, Irvine \\ David Krackhardt \\ Carnegie Mellon University
}

April 3, 2011

\begin{abstract}
This paper explores the role of local structural conditions that facilitate or hinder violence when enmity is present between parties. This is illustrated by examining violence among street gangs. Using structural balance theory, the current research investigates whether certain triadic structures in which two rival gangs $i$ and $j$ are related to a third gang with either an ally or rival relationship is linked to the level of violence between $i$ and $j$. Using multiple regression quadratic assignment procedure (MRQAP), the data on inter-gang relations and violent incidents among the gangs in Long Beach, CA, are analyzed. Structural imbalance, which indicates the lack of clear coalition patterns and a dominance relation, increases violence between rival gangs. On the other hand, the effect of balanced structures on violence is more complex. Balanced structures are much less violent, however, a gang will initiate violence if by doing so it can expect to reinforce its dominant position.
\end{abstract}




\section{Violence in the "Balance": A Structural Analysis of How Rivals, Allies, and Third-Parties Shape Inter-Gang Violence}

"People don't even have to say anything. If they don't like each other, if they've been beefing, fighting before, at war... just a look can set it off"

- KING 5 News, reporting on local gang violence (November 24, 2008)

When entities compete within the same social system, tension is inevitable. This is true whether one is referring to partners involved in a romantic situation, organizations competing for resources or market shares, or nation states wanting to further a national agenda. However, while tension may be inevitable, resolution of the tension by means of a violent act is not, and in fact, most tensions are resolved through non-violent means. Thus, domestic discord within a marriage does not always lead to domestic violence just as tensions between nation states do not always escalate into open warfare. But what distinguishes those sets of tensions that are resolved peacefully from those that erupt in violence? To answer this question, one must consider the broader landscape of social ties that link members of a system to one another. For instance, negotiation and diplomacy can often resolve issues peacefully, but in all cases, the success (or failure) of efforts aimed at preventing a conflict depends upon relationships that extend beyond the parties directly involved in the conflict (Dixon 1996). Hence, the presence and absence of ties to other members in the social system as well as the nature of these ties must be taken into account in order to better predict the eruption of violence.

When nations decide to wage war they first carefully survey the larger landscape of international relations being careful to not only assess the strengths of one's opponent but also to 
assess whether there are other nations that the potential opponent might pull into the conflict (Gartner and Siverson 1996). Acts of interpersonal violence are no different. Even when committed by a single offender against a single victim, the decision of whether to engage in, or desist from, an aggressive situation is often shaped by assessing the roles and actions of others (Felson and Steadman 1983; Luckenbill 1977). Among two actors, violations of a particular "code of the street" may go un-enforced, but when committed in the presence of a group, group norms and peer-pressure may require that "justice" be meted (Gould 2000; Horowitz and Schwartz 1974). Similarly, a smaller combatant may back down from a challenge from a physically more powerful foe unless third parties are present and can be expected to offer their aid should the fight get out of hand (Cooney 1998; Phillips and Cooney 2005).

Gang violence continues to be a problem affecting many communities. While many studies have been undertaken to shed light on the understanding of the mechanism underlying gang violence, most of these studies focus on the actions and characteristics of individuals (e.g., Battin et al. 1998; Esbensen and Huizinga 1993). Such studies persist despite the fact that gangs are largely group phenomena where individual identity often yields to group identity and an encounter of two individuals is perceived as an encounter of two group members (Short 1998; Tajfel 1982). Given the group nature of gangs and the presence of rivals and allies that characterize inter-gang relations, it is particularly important to understand to what extent a violent action of one gang toward another is influenced by their relations with other gangs. Though the opening quote seems to suggest that inter-gang violence has an element of randomness or unpredictability that might not lend itself to structural analysis, we argue that only by examining the structure of the relationships that bind gangs within a social context can one begin to better understand the occurrence and the level of inter-gang violence. 
In this research, we explore structural explanations for differential violence among gang rivals. ${ }^{1}$ Gangs are embedded in a network of rivalry/ally relations, and the patterns of violence between gangs also take the form of a network. Our empirical analysis focuses on testing propositions drawn from balance theory about the effect of such micro structural conditions on violence between two gangs. Balance theory informs us how third parties are related to the principal parties in conflicts, which shape the outcome of the dyadic conflicting relationship. The data we use to test the propositions are social network data based on police reports of conflicts and violence among street gangs in Long Beach, CA. Our model employs multiple regression quadratic assignment procedure (MRQAP) to adjust for the dependent structure in the network data. The results show that after controlling for various possible explanations, structural conditions are robust predictors of the levels and the directions of inter-gang violence.

\section{Relational Structure of Conflicts}

\section{Third Parties}

The outcomes of any conflicting relationship, whether it escalates (i.e. towards violence) or deescalates (i.e. with accommodation, withdrawal), hinge upon the physical, temporal, and relational context of the conflict. In sociology as well as in criminology, accumulated evidence on the relational structure of conflicts argues for, not only the importance of the nature of the dyadic relationship between the principal parties in conflict, but also for a crucial role often played by third parties. The role of "third parties" has been useful in understanding conflict in a variety of social contexts including interpersonal fights (Cooney 1998; Felson and Steadman 1983; Luckenbill 1977; Phillips and Cooney 2005), domestic violence (Baumgartner 1993), group conflicts in a feuding society (Gould 1999), and collective violence such as food riots and 
lynching (Auyero and Moran 2007; Senechal de la Roche 2001). Notably, several researchers examine the role of third parties by focusing on how the third party relates to the two combatants rather than merely considering whether a third party was present in the conflict (Baumgartner 1993; Phillips and Cooney 2005; Senechal de la Roche 2001).

Though these studies have made a valuable contribution to our understanding of how relational contexts shape the course of the conflict, their focus is restricted to the role of particular third parties (for example, a third party that is present at the time of a dispute between two individuals) and ignore the effect of third parties in the presence of the larger context. That is, triples (a conflict dyad and a third party) rarely occur in isolation; they are most likely to be embedded in patterns of relations with other parties. It is the move towards this more complete context that can provide additional important insight into the outcome of a conflict. This approach of assessing the role of third parties has been implemented within the framework of social network analysis and has proved to be fruitful in political science and the study of international relations (Dorussen and Ward 2008; Maoz et al. 2007). Yet despite the long line of research on the impact of the characteristics of social networks and positions within a network on a wide range of individual and group behaviors, there has been relatively little sociological research on the network effect of third parties on conflicts. We attempt to fill this gap by examining the impact of third parties on inter-gang conflicts as they are embedded in a social network of rivalry and ally relations with other gangs.

\section{Social Network of Gangs and Violence}

Historically stable, antagonistic relations among gangs allow us to address the structure of conflict relationships and to examine how the structure of conflict relationships is related to 
the actual violence. Rivalry is intrinsic to street gangs, and rival gangs battle to gain respect and street reputation (Thrasher 1927/1963). ${ }^{2}$ As gangs have protracted enemies, they also maintain allies with other gangs (Decker and Van Winkle 1996). This network of rivalries and allies provides a unique structure that researchers interested in gang violence are just now beginning to explore.

One way in which social network analysis has been used is to treat relations among gangs as a network, where gangs, as a node, are tied to one another by rivalries and allies (Tita 2006). Using spatial regression techniques, Tita (2006) finds that the spatial distribution of gang violence is better explained by socio-spatial gang rivalry networks rather than geographic proximities. Another way is to treat interactions between gangs such as inter-gang violence as a network. Papachristos (2009) examines the network of murders among Chicago gangs and finds that the struggle for dominance and social status results in stable patterns of gang violence.

In the network analysis of gangs, it is important to distinguish between relations and interactions; in particular, violent interactions. Relations can be described as negative (hostile, conflicting), positive (friendly, allying), or null (no relationship). On the other hand, for our purposes, interactions are defined by whether or not a negative relation escalates to a violent incident, because certain negative relations might result in a violent interaction and others may not (Moore 1987). Observations from inter-state conflicts illuminate the point: "Rivalries represent relationships of mistrust, suspicion, and antagonism...Yet they do not necessarily entail intensive conflict in overly manifested fashions...A few rivalries will break out into war but, by no means, can one equate rivalry with war" (Colaresi, et al 2008: 193). The longstanding rivalries among gangs may be viewed as a latent construct in that over any given time frame, one may or may not observe violent interactions among a set of rivals. Despite the negative 
relationship being an obvious precursor to violent confrontation, the important question remains as to why some rivals end up fighting while others remain relatively quiet.

\section{Balance, Dominance and Conflict within Triads}

Balance theory was conceived by Heider (1946) as a psychological theory describing the interdependent nature of human relations. The choice to maintain a "positive" or "negative" relationship (usually interpreted as affective attributions made by the actors toward each other) with an individual is dependent upon the nature of existing relationships with other actors. The smallest social unit of analysis in which one can measure "balance" is the triad. Therefore, for any given actor (i) who has a relation with two other actors ( $\mathrm{j}$ and $\mathrm{k}$ ), actor i experiences balance if and only if two of the three relations among these three actors are negative (and the third relation is positive) or all three relations among these three actors are positive. Often, the balanced triples are described in terms of the classic proverb: 1) A friend of a friend is a friend; 2) an enemy of a friend is an enemy; 3) a friend of an enemy is an enemy; 4) an enemy of an enemy is a friend. Any other combination would be considered imbalanced.

Cartwright and Harary (1956) are credited for providing sociologists with a formal mathematical framework of graph theory to explore the structural properties induced by balance. The formalization and generalization of balance theory by Cartwright and Harary allowed many sociologists over the years to explore social structure and group processes. In a dynamic analysis of both real data and simulated data, it was shown that social structures tend to move towards balance over time (Doreian et al. 1996; Doreian and Krackhardt 2001; Hummon and Doreian 2003). In equilibrium, the dynamic tendency to stable state results in cross-sectional patterns, which allows researchers to make static predictions. For example, in a series of studies of 700 
social groupings, Davis $(1970,1979)$ and Holland and Leinhardt (1971) demonstrated that balanced triples occur much more frequently than would be expected by chance. These studies support the assertion that balance is a stable state of social structure.

One aspect of balance theory is of particular importance to the current research. When the principles of balance are satisfied, they describe a situation in which the boundary between friend and foe is clearly drawn ("you're either with us and are our allies or you're against us and are our enemies"). ${ }^{3}$ Importantly, when the boundary is drawn, a coalition/alliance emerges where a two-party alliance faces a lone adversary. Two triads in Figure 1 (NP and PN) describe such balanced structures. In contrast, imbalanced triads represent a situation in which these boundaries are not so clear. An imbalanced triadic structure is characterized by ambiguity as to who one's enemies are and who one's friends are. For example, if a friend of a friend is an enemy, then there is uncertainty as to whether the focal person's friend will be more loyal to them or instead to their other friend (the focal person's enemy). In triad $\mathbf{N N}$ depicted in Figure $1, i$ and $j$ share a common enemy $k$, and are enemies themselves. In triad $\mathbf{P P}$ depicted in Figure $1, i$ and $j$ are enemies despite the fact that they share a friend, $k$.

In order to understand the relationship between balance and the likelihood of violence between two focal parties, we draw on what Gould (2003) calls dominance relations. In his book "Collision of Wills", Gould (2003) argues that a conflict between two parties is hard to resolve and likely to result in violence when the cues regarding which party occupies the dominant position are unclear or under threat. Dominance relations are asymmetric relations that locate one party in a higher position than the other such as parents and a child, an employer and a worker, and a master and a slave. The asymmetric relations are less susceptible to violent conflict and are stable because rank is not contested, while symmetric relations, where no dominant position 
exists, are unstable and more likely to experience higher level of violence because both parties strive to take a dominant position. Since the stake of the conflict is the dominance of the relation, a trigger of a violent clash is often seemingly trivial (e.g., a disrespectful stare) and not necessary materially or monetarily significant. As the opening quote describes, this is especially true in an honor based society such as the one of street gangs where the symbolic meaning of an action is as important as its physical consequence (Horowitz 1983; Anderson 1999). In other words, if honor is important, a disrespectful action, no matter how trivial it might seem, carries a symbolically significance. Thus, defending it by the means of violence is no longer unreasonable, and according to Gould (2003) such disrespectful action can set off a violent event more easily in symmetric relations than in asymmetric relations. Papachristos (2009) shows that it is the competition for dominance, which he measures as the amount of overlapping turf among rivals, that is an important predictor for inter-gang violence.

Gould extends the argument of dominance in dyadic relations to those that involve third parties. This extension is significant because the third party introduces the possibility of an individual actor being outnumbered and dominated by the coalition between the two others (Simmel 1955[1922]; see also Caplow 1956). Triads comprising of rival gangs will be balanced and asymmetric when a lone gang is faced with two hostile rivals that share an allied relationship. Given that other factors such as gang size, which indicate status and physical advantage (Papachristos 2009), are comparable, gangs that are allied with a third gang are clearly in a position of dominance in such a structure. On the other hand, when a triad is characterized as being imbalanced, the relations will be symmetric among the gangs (all are enemies), and there is no clear indication of who dominates whom. ${ }^{4}$ We posit the following hypothesis and propose an empirical test of the relationship between balance and the level of violence. 
Hypothesis 1: Rival gangs in imbalanced triads engage in more violence than the gangs in balanced triads.

[Insert Figure 1 about here]

\section{Method}

\section{Data}

Our data are from the Long Beach Police Department (LBPD). The network data identify the rivalry and ally relationships among 40 known gangs in Long Beach. We also have attribute data for each of the gangs including the race/ethnicity of the gang (Asian, Black, Latino, White, Pacific Islander, Samoan, and Mixed), and the number of members in the gang. The information of the relationships among the gangs is based on expert knowledge, namely from gang detectives in LBPD. The LBPD also provided official crime data on the count of inter-gang violent incidents. There were 105 violent incidents identified as incidents involving shootings between the 40 gangs for the period 2002 through $2005 .{ }^{5}$

The original file provided by the LBPD contained 887 incidents that were clearly identified as gang involved (either victim or attacker is identified as a gang member). Of these, 157 incidents qualify as gang-on-gang incidents where both victim and attacker were identified as gang members. The remaining incidents either involved individuals who were not gang members or incidents where the identity of the victims or offenders was unknown. An additional 53 incidents involved members of gangs from areas outside of Long Beach providing 105 incidents in which the attacker and the victim are identified as one of the 40 gangs. Though the need for complete dyadic information excludes many of the incidents, there is no reason to believe that the final sample is biased to include some gangs but not others. 
It is important to note that there is a clear distinction between how a rivalry relationship is assigned to a pair of gangs and whether there is a violent incident occurring between the pair of gangs. As seen in other group-based conflicts (i.e., national, ethnic, religious), the negative intergang relationships are institutionalized and not necessarily based on some particular previous incidents (Maxson, Gordon, and Klein 1985). Thus, the enemy relationships identified by the gang detectives are relatively long standing, historical relationships among the gangs.

Figure 2 shows the network of gangs in Long Beach. The gangs (squares) are either connected with enemy relations (thick lines), friendly relations (thin lines), or no identifiable relation (no line). The enemy relations $(n=45)$ outnumber the friendly relations $(n=25)$. Figure 3 visualizes the presence and the level of violent incidents among the LB gangs with the coordinates of Figure 2 retained. The picture supports the claim that gang relations are not simply a reflection of recent incidents; not all enemy relations are accompanied by violent incidents. Hence, the objective of this paper is to discern the additional power of gangs' structural positions over the mere presence of historical hostile relations to explain the variation in the frequency of inter-gang violent incidents.

[Insert Figures 2-3 about here]

\section{Measures}

\section{Dependent Variable}

The dependent variable, the count of violent incidents among the 40 gangs, is presented in a matrix. The rows and the columns of the matrix correspond to attacker gangs and victim gangs respectively. The entries $\langle\mathrm{i}, \mathrm{j}\rangle$ of the matrix denote the number of violent incidents perpetrated by gang $i$ against gang $j$. For example, a 3 in the cell $\langle 9,5\rangle$ of the matrix would 
indicate that gang number 9 committed three acts of violence against gang number 5 over the four years included in this study.

Similar to the dependent variable, the independent variables are represented as matrices. Some of the independent variables are strict control variables, permitting us to address possible alternative explanations for any observed results. Other independent variables represent the structural conditions that are the focus of this study.

\section{Explanatory Structural Variables}

Our interest is not in the near-tautological, dyadic-level prediction that violence occurs between enemies. Instead, we want to better understand why some enemy ties are more likely to induce violence than are others by exploring the impact of the presence of a third actor. More specifically, as discussed above, we would like to test the two competing predictions regarding the relationship between balance and the level of violence. Thus, we construct a set of variables that capture the balanced and imbalanced triadic structure in which a pair of enemy gangs are embedded. In other words, these variables denote the patterns of relationships that the pair of rival gangs have with a third gang, either an enemy or an ally, and the patterns represent either balanced or imbalanced triads. We present the construction of two imbalanced triads followed by two balanced triads.

Imbalanced Triples. $\mathbf{N N}$ : The first structural variable that represents an imbalanced triad is the all-enemy triple (Figure 1). Given that there is an enemy tie between $i$ and $j$, the question we want to address is whether such a tie is embedded in many $\langle i, k, j>$ triples wherein all three gangs are enemies of each other. That is, how many triples does the $\langle i, j\rangle$ pair belong to that are of this type? This number is easily calculated in two steps. The first step captures the number of 
triples $\langle\mathrm{i}, \mathrm{k}, \mathrm{j}>$ wherein $i$ is an enemy of $k$ and $k$ is an enemy of $j$. The second step ascertains whether $i$ and $j$ are themselves enemies.

The "enemy" matrix, denoted as $\mathbf{N}$ (for "negative" ties), captures whether a pair of gangs $<\mathrm{i}, \mathrm{j}>$ has an enemy relation. Thus, $\mathbf{N}_{\mathrm{i}, \mathrm{j}}=1$ if and only if $i$ is judged to be an enemy of $j$; else $=0$. The matrix (inner product) multiplication of $\mathbf{N}$ times itself gives the number of two-step links for each pair of nodes. That is, $\mathbf{N N}_{\mathrm{i}, \mathrm{j}}=$ the number of $k$ 's that exist in $\mathbf{N}$ such that $i$ has an enemy tie with $k$ and $k$ has an enemy tie with $j$. This is exactly the number we need for step one. We are only concerned with those cases, however, where $i$ is also an enemy of $j$. We can capture this subset by element-wise multiplying $\mathbf{N N}$ by $\mathbf{N}$ again, yielding $\mathbf{N} \mathbf{N} \cdot \mathbf{N}$. The result of this compound relation is that $\mathbf{N N} \cdot \mathbf{N}_{\mathrm{i}, \mathrm{j}}=$ the number of $k$ 's that have enemy relations to both $i$ and $j$ if $i$ and $j$ are enemies; else, $\mathbf{N N} \cdot \mathbf{N}_{\mathrm{i}, \mathrm{j}}=0$. That is, it is the number of $\langle\mathrm{i}, \mathrm{k}, \mathrm{j}\rangle$ enemy triples of the form $\mathbf{N N}$ designated in Figure 1 for $i$ and $j$.

PP: The other imbalanced triad is in the form of two enemy gangs who have a common ally. The ally relation matrix, denoted $\mathbf{P}$ (for "positive" ties), is constructed in the same way. Thus, $\mathbf{P}_{\mathrm{i}, \mathrm{j}}=1$ if and only if $i$ and $j$ are judged to be allies; else=0. The variable name PP (Figure 1d) is calculated as PP·N. PP· $\mathbf{N}_{\mathrm{i}, \mathrm{j}}=$ the number of $k$ 's that have ally relations to both $i$ and $j$ if $i$ and $j$ are enemies; else $\mathbf{P P} \cdot \mathbf{N}_{\mathrm{i}, \mathrm{j}}=0$.

The next two structural variables represent the balanced triads.

Balanced Triples. NP: The first balanced triad is described as a triad where gang $i$ is related to a third gang $k$ with an enemy tie while gang $i$ 's enemy gang $j$ is an ally of $k$. The variable name NP (Figure 1) is calculated as $\mathbf{N P} \cdot \mathbf{N} . \mathbf{N P} \cdot \mathbf{N}_{\mathrm{i}, \mathrm{j}}=$ the number of $k$ 's that have an enemy relation to $i$ and an ally relation to $j$ if $i$ and $j$ are enemies; else $\mathbf{N P} \cdot \mathbf{N}_{\mathrm{i}, \mathrm{j}}=0$. That is, it is the number of $\langle\mathrm{i}, \mathrm{k}, \mathrm{j}\rangle$ triples of the form NP represented in Figure 1 that $i$ and $j$ are embedded in. 
PN: The second balanced triad is a triad where gang $i$ is related to a third gang $k$ with an ally tie while gang $i$ 's enemy gang $j$ is an enemy of $k$. The variable name PN (Figure 1) is calculated as $\mathbf{P N} \cdot \mathbf{N}$. $\mathbf{P N} \cdot \mathbf{N}_{\mathrm{i}, \mathrm{j}}=$ the number of $k$ 's that have an ally relation with $i$ and an enemy relation with $j$ if $i$ and $j$ are enemies; else $\mathbf{P N} \cdot \mathbf{N}_{\mathrm{i}, \mathrm{j}}=0$.

In figure 1, the union of NP and PN represents balance and is named BALANCE, whereas the union of NN and PP represents imbalance and is named IMBALANCE. ${ }^{6}$

\section{$\underline{\text { Control Variables }}$}

While the hypothesized variables are clear, there are alternative explanations for differential violence rates that we must control for. First, it is important to remove the main effect of enemy relations, or more specifically, for the lack of allies or even neutral relations between gangs. The null relation, denoted $\mathbf{O}$, the complement of the union of the $\mathbf{N}$ and $\mathbf{P}$ relations, indicates that no relation exists between the two gangs. Thus, $\mathbf{O}_{\mathrm{i}, \mathrm{j}}=1$ if and only if $i$ and $j$ have neither an enemy nor an ally relation with each other; else $=0$.

We also control for the sizes of the gangs. One could argue that large gangs are more likely to attack others because they are fearless. Likewise, small gangs are more likely to be attacked because they are easy marks with fewer resources for retaliation. It is also important to control for the gang sizes because they are an indicator of power and status. Since these size effects could be confounded with the effects of balance and the structural dominance in a set of relations, we control for this potential alternative explanation by creating a control variable: Size Difference. Size Difference is defined as the difference between the number of members in the attacking gang, Attacker Size (AS), and the number of members in the attacked gang, Victim Size (VS). Specifically, $\mathbf{A S}_{\mathrm{i}, \mathrm{j}}=$ the size of gang $i$; $\mathbf{V S} \mathbf{i}_{\mathrm{i}, \mathrm{j}}=$ the size of gang $j$. The attacker sizes are 
recorded in a column vector of length 40; each element describes the number of members in each of the 40 gangs. The vector was repeated 40 times to construct the 40 by $40 \mathrm{AS}$ matrix. The victim sizes are similarly recorded, but instead of in a column vector, they are collected in a row vector of length 40 . The row vector was repeated 40 times to create the 40 by 40 VS matrix. Size Difference is then calculated by subtracting VS matrix from AS matrix element-wise.

Given the territorial nature of gangs, we expect the probability of any interaction to decay with distance. The variable Geographical Adjacency; Geographical Adjacency ${ }_{\mathrm{i}, \mathrm{j}}=1$ if and only if gang i's turf is adjacent to gang j's turf; else=0. The geographical adjacency of gang turfs is important to control because it creates a condition under which the size difference between rival gangs would make it clear which gang is dominant (i.e. a small gang is more likely to be dominated by a large rival gang if the turfs of the two gangs are located close to one another).

Another individual characteristic of gangs that could signify the status is their ferociousness. One might expect that some gangs simply have a higher propensity to attack (“aggressiveness"), while other gangs are more likely to be victimized ("vulnerability"). The variable \# Attacks includes the total number of incidents initiated by a gang regardless of whether or not the victim was a gang member; \# Attacks $\mathbf{s}_{\mathrm{i}, \mathrm{j}}=$ the number of attacks that gang $i$ committed. Similarly, the variable \# Victimized is the number of times each gang was attacked by other gang or non-gang members. These two variables are constructed in the same way as how the size variables are created; \# Attacks from a column vector and \# Victimized from a row vector. As mentioned in the Data section, the original incident file provided by the LBPD contained all gang related violent incidents. The two controls, \# Attacks and \# Victimized, are constructed as individual gang level variables to capture each gang's aggressiveness and 
vulnerability by utilizing all incidents where the gang affiliation of at least one party (offender or victim) is known.

The gangs in Long Beach are overwhelmingly homogeneous with respect to race and ethnicity (including Asian, Black, Latino, White, Pacific Islander, and Samoan). From the literature, we also know that gang violence is characterized largely by intra-race and intra-ethnic

phenomena (Block 1993; Klein 1995; Maxson et al. 1985). Therefore we control for the match of race and ethnicity between gang $i$ and gang $j$. The variable controlling for this effect is Ethnicity Match; Ethnicity Match $_{\mathbf{i}, \mathrm{j}}=1$ if and only if gang $i$ 's race/ethnicity is the same as gang $j$ 's race/ethnicity; else $=0$. There is only one "mixed" race gang among the 40 gangs, so its rows and columns are all zeros. ${ }^{7}$

\section{Analysis}

Network data by their very nature violate the assumption of independence. For instance, knowing that "A" and "B" share a relationship and that " $\mathrm{B}$ " and "C" share a relationship, then the A-B dyad can not be assumed to be independent of the B-C dyad given B's relationship with both A and C. Using standard OLS estimation, the lack of independence will result in biased estimates of the standard errors, which can lead one to draw the wrong conclusions when conducting hypothesis tests. Thus, we use multiple regression quadratic assignment procedure (MRQAP) to examine the relationship between the independent variables that include the controls and the dependent variable, which is the frequency of violent incidents (Dekker, Krackhardt, and Snijders 2007; Krackhardt 1988).

MRQAP is a procedure that is suitable to determine an association between matrices when there is an autocorrelation in the data as is the case in the dyadic network data. It provides 
a statistical significance test by randomly permuting the dependent variable matrix and calculating a regression statistic every time the matrix is permuted. This random permutation will produce a reference distribution, against which the observed statistic is compared. The statistic is deemed significant if a critical fraction of the statistical values generated under permutation of the data are less than (or greater than) the observed statistical value. Thus, in the permutation test, the statistical test is conditioned on the autocorrelation in the data. Dekker, Krackhardt, and Snijders (2007) found that different methods of performing this permutation test were not equivalent. Further, they discovered that a new method they developed, called "Double SemiPartialling" available in UCINET (Borgatti, Everett, and Freeman 2002) is robust against a variety of reasonable conditions. Relevant to the present case, they found that when a model consisted of a dependent variable comprised of counts, that under conditions of network autocorrelation, multicolinearity, and skewness, the MRQAP test is statistically unbiased if one employs a pivotal statistic as the reference statistic in the permutation tests. In accordance with their recommendations, we use a pivotal statistic (the t-statistic) in the tests of these regression parameters.

\section{Results}

The descriptive statistics and the correlations among the variables are shown in Table 1. The average number of attacks each gang committed against other gangs is $2.73(=.07 * 39)$. The zero-order correlations in Table 2 show that both BALANCE and IMBALANCE are positively correlated with our dependent variable. It is our interest to examine these two effects when other variables are controlled for using MRQAP. The MRQAP results testing the basic prediction models are summarized in Table 2. The coefficient is the change in the dependent variable - the 
number of violent incidents between rival gangs - for every one unit increase in each independent variable, while keeping other independent variables constant. Remember that the structural variables represent all configurations of $\langle\mathrm{i}, \mathrm{k}, \mathrm{j}\rangle$ triples where the $\langle\mathrm{i}, \mathrm{j}\rangle$ pair is negative (enemy). As expected, the coefficient estimates for Ally relation and Null relation are negative, which indicates that the presence of an ally relationship or the absence of either an ally or an enemy relationship is associated with the lower likelihood of violence between rival gangs $i$ and $j$.

The results for Model 1 suggest that there is a small negative relationship $(\beta=-.051)$ between balance and the number of violent attacks, but the relationship does not reach statistical significance. Thus the extent to which one's enemy is an enemy of a friend or a friend of an enemy only has a marginally negative effect on the extent to which the gang will inflict violence on that enemy. Balance in this case seems to predict very little. On the other hand,

IMBALANCE (Model 2) is convincingly and positively related to the number of violent attacks ( $\beta=.835)$. The MRQAP test yields a p-value less than .001. The size of this coefficient IMBALANCE is worth explaining.

As the degree of BALANCE surrounding the gang's enemy relations increases, there is no significant associated change in violence along those relations. But, as the extent of IMBALANCE along those same negative ties increases, the frequency of violent confrontations increases markedly; for each imbalanced triple surrounding the negative tie, on average there is almost one more (.8) violent incident. Model 3, containing both IMBALANCE and BALANCE as predictors, essentially confirms the results of Model 1 and Model 2.

Let us reiterate the hypothesis regarding the relationship between balance and violent attacks: imbalance is linked with a higher level of violence due to the ambiguity of who one's friends are and who one's enemies are and the resulting reality of a contested dominant position. 
Although balance is weakly associated with a lower level of violent attacks, the fact that balance seems not to have a strong relationship with the count of violent incidents prevents us from firmly determining whether the hypothesis is supported. However, the strong negative link between IMBALANCE and the level of violence suggests that imbalance in fact induces a much higher probability of violent attacks from gang $i$ to gang $j$. Thus, the combined results support the hypothesis and its attendant argument that a preponderance of imbalanced relations leads to violence due to the lack of stable dominance relations.

It is worth noting that structural variables contribute substantial explanatory power to the model. The adjusted R-squared for the baseline model with dyadic relationships ( $\mathbf{N}$ and $\mathbf{P}$ ) is .088. After including structural variables, the adjusted R-squared becomes .212. This provides evidence that the patterns of relationships with the third party help explain the violence over and beyond the dyadic relations.

[Insert Tables 1-2 about here]

\section{Beyond Balance}

Balance theory thus does not differentiate between the two balanced triads, NP and PN. However, within the context of gang violence (and many other social relationships) NP and PN represent very different constructs. In our data, the directionality of the violence is an important feature as gang $i$ is defined as an attacker and gang $j$ as a victim. In NP gang $i$ is surrounded by a coalition of enemies, whereas in PN gang $i$ is a member of the coalition facing a lone target. In developing a hypothesis regarding the direction of violence between rivals in balanced triads, we go back to the theory that generated our first hypothesis on the relationship between balance and the total level of violence between rival gangs. Consider first PN - from gang $i$ 's perspective 
having gang $k$ as an ally represents a structure in which an attack on gang $j$ might work to reinforce or maintain its dominance. From gang j's perspective, the structure represents an imposing force that is constraining it from unleashing any violence against its enemy $i$, who is backed up by the other enemy $k$. Thus, we propose the following hypotheses regarding structural conditions predict more violent attacks by gang $i$ on gang $j$ within the two triadic structures, NP and $\mathbf{P N} .^{8}$

Hypothesis 2: Gang $i$ in $\mathbf{P N}$ balanced triads engage in more violence against gang $j$ than in $\mathbf{N P}$ balanced triads.

To explore the directionality of violence and examine the effect of NP and PN on the number of attacks initiated by gang $i$ against gang $j$, we separated the BALANCE variable into its two constituent parts, NP and PN and added them separately in a subsequent MRQAP equation (Table 3). The results are consistent with the hypothesis. The results indicate that those gangs faced with NP triples are much less likely to initiate violence against $\operatorname{gang} j$ ( $\beta=-.193, p$ $=.002)$. This is a much stronger effect than when we pooled all balanced relations together $(-$ .051). Moreover, by contrast, when the structure is characterized by gang $i$ having a positive tie with an enemy of $j(\mathbf{P N})$, gang $i$ is more likely to instigate violence $(\beta=+.116, p=.020)$, even though it is still a balanced relation. This is consistent with the "reinforcing dominant position" explanation. Clear, unambiguous, balanced relations will discourage gangs from instigating violence if the balance emphasizes the coalition of gangs that is dominating the triadic structure (NP). ${ }^{9}$ If, however, the balance indicates a coalition on the part of gang $i(\mathbf{P N})$, then gang $i$ is located in a favorable prospect of maintaining the status quo dominance, resulting in somewhat more acts of violence instigated against $j$. 
Model 5 (Table 3) includes both balanced relations (NP, PN) and IMBALANCE. The model also includes incomplete triads (NO, OP, PO, ON). ${ }^{10}$ They are missing either the i-k relation or the j-k relation (figure 4). They essentially represent weaker versions of complete triads (NP, PN) and help us understand which relation with the third party, $i$ 's relation with the third party (i-k) or j's (the enemy of $i$ ) relation with the third party $(\mathrm{j}-\mathrm{k})$, dictates whether $i$ will attack $j$ or not. In terms of the magnitude and the direction of $\mathbf{N P}$, and $\mathbf{P N}$, the results are the same as the ones from Model 4. Indeed, we find that while clear coalitions on the part of gang $j$ represented by the NP triple reduces $i$ 's aggressive behavior, it pales in comparison to the effect of imbalanced triples, which still dominate in predictive power $(\beta=.836) .{ }^{11}$ The coefficients on the incomplete triads show that the fact that the enemy has an ally is an important explanation for why $i$ is restrained to attack $j$ in $\mathbf{N P}$, and the explanation for more violence by $i$ in $\mathbf{P N}$ comes from the combination of $i$ having an ally and the ally being an enemy of $j$, not from one relation or the other.

\section{[Insert Table 3 about here]}

\section{Conclusion}

The findings of this paper indicate that the structures of inter-gang rivalries and allies have important implications for patterns of violence. Seemingly random violent attacks that occur between rival gangs are in fact constrained by certain patterns of relations that gangs form among themselves, an observation that will be missed if one looks only at dyadic relationships. Beyond the role of particular third parties in the outcome of dyadic conflict, the current research demonstrates the advantage of examining the indirect relationship between the two parties in conflict via the third embedded in the larger context. 
This study uses balance theory as a framework for understanding how certain patterns of affinity and enmity in a triad creates a situation in which conflict between rivals is likely to evolve into violence. The findings partially support the link between balance theory and the level of violence. Our first set of results is consistent with the hypothesis that imbalance has a catalytic effect on violence due to its ambiguous or invalidated dominance relationship between rival gangs. As we probe into the directionality of violence in balance, we reveal evidence that is consistent with the role of violence in reinforcing dominance within a balanced structure.

It should be noted that we successfully controlled for the alternative explanations of the frequency of violence from $i$ to $j$. We also controlled for the characteristics of individual gangs or dyads of gangs that signify power and status (e.g., gang size difference, aggressiveness), which could confound the effect of structural dominance (coalition). The coefficients on the null relation and the ally relation are large and negative. That is, they reduce the number of violent attacks. This is consistent with our baseline prediction that having a rival relation leads to more violence. Attribute-level controls appear to explain relatively little about the occurrence of violence. Having another enemy as an attacker changes a mere 1/100 of an act of violence perpetrated by the attacker on the victim. It is true that the attacker's propensity to initiate violence or the victim's vulnerability to be attacked increases the number of attacks, but the magnitude is far from substantial $(<.01)$.

The value of using basic descriptive network analysis of gang rivalries in the design and implementation of violence reduction strategies has been demonstrated on numerous occasions. Braga et al. (2001) and Tita et al. (2003) use network analysis in Boston and in East Los Angeles respectively to determine which gang rivalries should be the primary target for the intervention. The current work takes the next step and assesses the actual levels of violence by considering the 
structure of relationships within a system of gang rivalries and allies. This more nuanced approach can help in the formulation of effective strategies aimed at reducing gang violence by identifying those gang conflicts that are most likely to escalate into violent acts. These implications, in turn, can be useful in contexts beyond gang structures, in which the question of whether any type of conflict escalates (or not) to violence, needs to be answered. 


\section{Notes}

1. We focus our attention on the structural explanation of violence that occurs among gangs that were identified as "rivals." Out of 105 violent incidents, 65 of them $(62 \%)$ occurred in a rival relationship, 34 of them (32\%) occurred in gangs with no relationship, and 6 of them (6\%) occurred in ally relationships. Considering the distribution of dyad types, of the 90 dyadic rivalry relationships, violence occurred across 23 percent of them (21 events). Among ally relations violence occurred in $6 \%$ of such instances ( 3 of 50), and among all possible "no relationship" dyads (more than 1400), violence only occurred in 20 (or $1.4 \%$ ) of such (non-) relations. 2. As sociological literature has long recognized (Coser 1956; Gould 1999, 2000; Simmel 1955 [1922]), having a rival gang as an external threat strengthens the cohesion and solidarity within the gang (Klein and Crawford 1967; Short and Strodtbeck 1963, 1965; Suttles 1968).

3. In fact, the structure theorem (Cartwright and Harary 1956) presents a rather remarkable mathematical property. If all triads within a network are balanced, the nodes can be partitioned into two sets such that every node within the same set is connected with a positive tie, and is connected to nodes in the other set with a negative tie. Political scientists recognized that such balanced structure is thus bipolarized; the distinction between friends and foes is clearly drawn by to which bloc of states one belongs to (Hart 1974; Waltz 1964).

4. A similar theoretical argument is found in a study of international relations and conflicts: imbalanced relations are characterized by "uncertainty and mistrust" and "the temptation to launch preventive conflict in such cases is especially high" (Maoz et al. 2007: 104). They found evidence that is consistent with the argument: countries embedded in imbalanced relations with other countries were more likely to engage in military conflicts with each other. 
5. It is fair to point out that a gang's antagonistic acts against another gang often take forms other than violence, such as threatening graffiti and disrespectful remarks toward members of rival gangs. However, acts of violence are signs of culminated aggression from one gang against another, which present a great risk of initiating a cycle of retaliation. Considering this critical consequence of violence, it is not unreasonable to speculate that the decision to physically attack a rival gang involves a whole gang, not simply the momentary acts of individual members. 6. It should be noted that in our data there is only one PP triad. Therefore, IMBALANCE is mostly represented by the $\mathbf{N N}$ structure.

7. There are several other controls considered in the models. It seems plausible that an increase in the number of enemies will likely increase the probability of being involved in violent acts. In addition, such gangs could also induce more gang violence towards them. To control for the number of enemies, we include Attacker Enemy Degree (AED), the number of enemies that the attacking gang has, and Victim Enemy Degree (VED), the number of enemies that the victimized gang has. Conversely, a gang with many allies may be less likely to feel threatened or feel the need to attack others; and such a gang may be less likely to be attacked because of the number of allies that might be called on to retaliate. In order to control for this possible confound with balance, we include Attacker Ally Degree (AAD), the number of allies that the attacking gang has, and Victim Ally Degree (VAD), the number of allies that the victimized gang has.

8. The hypothesis is consistent with the argument and empirical evidence by Phillips and Cooney (2005) who show that violence is likely to ensue when third parties have a favorable relationship with one principal combatant but no favorable relationship with the other; in other words, when the third parties have the potential to provide partisan support. 
9. Studies on international relations and conflicts show that NP structure deters attacking a rival because the rival has an ally (e.g., Sorokin 1994; Maoz 2006).

10. Due to the multicollinearity with the incomplete triads, the controls for degrees are not included in Model 5.

11. In the data, there are cases of violence where either the attacker or the victim gang name is unknown. We examined whether the patterns of known and unknown gangs are different. The chi-square test suggests that there are two gangs for which the patterns are significantly different. Once the two outlier gangs are removed from the analysis, $\mathbf{P N}$, which is relatively weak in Model 5 becomes insignificant. 


\section{References}

Anderson, Elijah. 1999. Code of the Street: Decency, Violence, and the Moral Life of the Inner City. New York: W. W. Norton \& Company.

Auyero, Javier and Timothy P. Moran. 2007. "The Dynamics of Collective Violence: Dissecting Food Riots in Contemporary Argentina." Social Forces 85:1341:1367.

Battin, Sara R., Karl G. Hill, Robert D. Abbott, Richard F. Catalano, and J. David Hawkins. 1998. "The Contribution of Gang Membership to Delinquency beyond Delinquent Friends" Criminology 36(1): 93-116

Baumgartner, Mary Pat. 1993. "Violent Networks: The Origins and Management of Domestic Conflict." Pp. 209-231 in Aggression and Violence: Social Interactionist Perspectives, edited by R. B. Felson and J. T. Tedeschi. Washington, DC: American Psychological Association.

Block, Carolyn R. 1993. "Lethal Violence in the Chicago Latino Community.” Pp. 267-342 in Homicide: The Victim/Offender Connection, edited by A. V. Wilson. Cincinnati, OH: Anderson.

Block, Richard L. and Carolyn Rebecca Block. 1992. "Homicide syndromes and vulnerability: Violence in Chicago community areas over 25 years." Studies on Crime and Crime Prevention $1: 61-87$. 
Borgatti, Stephen P., Martin G. Everett, and Linton C. Freeman. 2002. Ucinet for Windows:

Software for Social Network Analysis. Harvard, MA: Analytic Technologies.

Braga, Anthony A., David M. Kennedy, Anne M. Piehl, and Elin J. Waring. (September 2001). Reducing Gun Violence: The Boston Gun Project's Operation Ceasefire. National Institute of Justice Research Report. Washington, DC: National Institute of Justice.

Caplow, Theodore. 1956. "A Theory of Coalitions in the Triad." American Sociological Review 21:489-493.

Cartwright, Dorwin and Frank Harary. 1956. "Structural Balance: A Generalization of Heider's Theory." Psychological Review 63:277-293.

Colaresi, Michael P., Karen Rasler, and William R. Thompson. Strategic Rivalries in World Politics: Position, Space and Conflict Escalation. New York: Cambridge University Press.

Cooney, Mark. 1998. Warriors and Peacemakers: How Third Parties Shape Violence. New York: New York University Press.

Coser, Lewis A. 1956. The Functions of Social Conflict. New York: The Free Press.

Davis, James A. 1970. "Clustering and Hierarchy in Interpersonal Relations: Testing Two Graph Theoretical Models on 742 Sociomatrices." American Sociological Review 35:843-851. 
1979. "The Davis/Holland/Leinhardt Studies: An Overview.” Pp. 51-62 in Perspectives on

Social Network Research, edited by P. W. Holland and S. Leinhardt. New York: Academic Press.

Decker, Scott H. and Barrik Van Winkle. 1996. Life in the Gang: Family, Friends, and Violence. New York: Cambridge University Press.

Dekker, David, David Krackhardt, and Tom A. B. Snijders. 2007. "Sensitivity of MRQAP Tests to Collinearity and Autocorrelation Conditions." Psychometrika 72:563-581.

Dixon, William J. 1996. “Third-Party Techniques for Preventing Conflict Escalation and Promoting Peaceful Settlement.” International Organization 50:653-681.

Doreian, Patrick and David Krackhardt. 2001. "Pre-transitive Mechanisms for Signed Networks." Journal of Mathematical Sociology 25:43-67.

Doreian, Patrick, Roman Kapuscinski, David Krackhardt, and Janusz Szczypula. 1996. “A Brief History of Balance through Time.” Journal of Mathematical Sociology 21:113-131.

Dorussen, Han and Hugh Ward. 2008. "Intergovernmental Organizations and the Kantian Peace: A Network Perspective." Journal of Conflict Resolution 52:189-212. 
Esbensen, Finn-Aage and David Huizinga. 1993. "Gangs, Drugs, and Delinquency in a Survey of Urban Youth. Criminology 31(4):565-589.

Felson, Richard B. and Henry J. Steadman. 1983. "Situational Factors in Disputes Leading to Criminal Violence.” Criminology 21:59-74.

Gartner, Scott Sigmund and Randolph M. Siverson. 1996. "War Expansion and War Outcome." The Journal of Conflict Resolution 40:4-15.

Gould, Roger V. 1999. "Collective Violence and Group Solidarity: Evidence from a Feuding Society.” American Sociological Review 64:356-380.

_. 2000. "Revenge as Sanction and Solidarity Display: An Analysis of Vendettas in Nineteenth-Century Corsica.” American Sociological Review 65:682-704.

_. 2003. Collision of Wills: How Ambiguity about Social Rank Breeds Conflict. Chicago, University of Chicago Press.

Hart, Jeffrey. 1974. "Symmetry and Polarization in the European International System, 18701879: A Methodological Study.” Journal of Peace Research 3:229-244.

Heider, Fritz. 1946. “Attitudes and Cognitive Organization.” Journal of Psychology 21:107-112. 
Holland, Paul W. and Samuel Leinhardt. 1971. "Transitivity in Structural Models of Small Groups." Comparative Group Studies 2:107-124.

Horowitz, Ruth. 1983. Honor and the American Dream: Culture and Identity in a Chicano Community. New Brunswick, NJ: Rutgers University Press.

Hummon, Norman P. and Patrick Doreian. 2003. "Some Dynamics of Social Balance Processes: Bringing Heider Back into Balance Theory.” Social Networks 25:17-49.

KING 5 News. 2008. "Violent weekend raises concerns about gang war, November 24, 2008.” http://www.king5.com/localnews/stories/NW_112408WAB_gang_war_KC.1e6ed08ba.html.

Klein Malcolm W. 1995. The American Street Gang: Its Nature, Prevalence, and Control. New York: Oxford University Press.

Klein Malcolm W. and Lois Y. Crawford. 1967. "Groups, Gang, and Cohesiveness.” Journal of Research in Crime and Delinquency 4:63-75.

Krackhardt, David. 1988. "Predicting with Networks: Nonparametric Multiple Regression Analysis of Dyadic Data.” Social Networks 10:359-381.

Luckenbill, David F. 1977. “Criminal Homicide as a Situated Transaction.” Social Problems 25:176-186. 
Maoz, Zeev. 2006. "Network Polarization, Network Interdependence, and International Conflict, 1816-2002.” Journal of Peace Research, 43: 391-411.

Maoz, Zeev, Lesley G. Terris, Ranan D. Kuperman, and Ilan Talmud. 2007. "What is the Enemy of My Enemy: Causes and Consequences of Imbalanced International Relations, 1816-2001.” Journal of Politics, 69:100-115.

Maxson, Cheryl L., Margaret A. Gordon, and Malcolm W. Klein. 1985. "Differences between Gang and Nongang Homicides.” Criminology 23:209-222.

Moore, Joan W. 1987. "Variations in Violence among Hispanic Gangs.” Pp. 215-230 in Proceedings: Research conference on violence and homicide in Hispanic communities, edited by J. Kraus, S. Sorenson, and P. Juarez. Los Angeles, CA: University of California-Los Angeles.

Papachristos, Andrew V. 2009. "Murder by structure: Dominance relations and the social structure of gang homicide.” American Journal of Sociology, 115:74-128.

Papachristos, Andrew V. 2008. "Is Murder Transitive? Reciprocity, Balance, and Hierarchy in Gang Homicide Networks.” Manuscript.

Phillips, Scott and Mark Cooney. 2005. "Aiding Peace, Abetting Violence: Third Parties and the Management of Conflict.” American Sociological Review, 70:334-354. 
Senechal de la Roche, Roberta. 2001. "Why is Collective Violence Collective?” Sociological Theory 19:126-144.

Short, James F. Jr. 1998. "The Level of Explanation Problem Revisited - The American Society of Criminology 1997 Presidential Address." Criminology 36:3-36.

Short, James F. Jr. and Fred L. Strodtbeck. 1963. “The Response of Gang Leaders to Status Threats: An Observation on Group Process and Delinquent Behavior.” American Journal of Sociology 68:571-579. . 1965. Group Process and Gang Delinquency. Chicago, IL: University of Chicago Press.

Simmel, George. 1955 [1922]. Conflict and the Web of Group Affiliations. Glencoe, IL: The Free Press.

Sorokin, Gerald L. 1994. “Alliance Formation and General Deterrence: A Game-Theoretic Model and the Case of Israel." The Journal of Conflict Resolution 38:298-325.

Suttles, Gerald D. 1968. The Social Order of the Slum: Ethnicity and Territory in the Inner City. Chicago, IL: University of Chicago Press. 
Tajfel, Henri. 1982. “Social Psychology of Intergroup Relations.” Annual Review of Psychology 33:1-39.

Thrasher, Frederic. 1927/ reprint1963. The Gang: A Study of 1313 Gangs in Chicago. Chicago, IL: University of Chicago Press.

Tita, George E. 2006. Neighborhoods as nodes: Combining social network analysis with spatial analysis to explore the spatial distribution of gang violence. Conference paper for Workshop on Space, Networks, and Social Influence. February $9^{\text {th }}-11^{\text {th }}, 2006$. University of California, Irvine.

Tita, George E., K. Jack Riley, Greg Ridgeway, Clifford Grammich, Allan F. Abrahamse, and Peter W. Greenwood. 2003. Reducing Gun Violence: Results from an Intervention in East Los Angeles. Santa Monica, CA: RAND Corporation.

Waltz, Kenneth N. 1964. “The Stability of a Bipolar World.” Daedalus 93:881-909. 

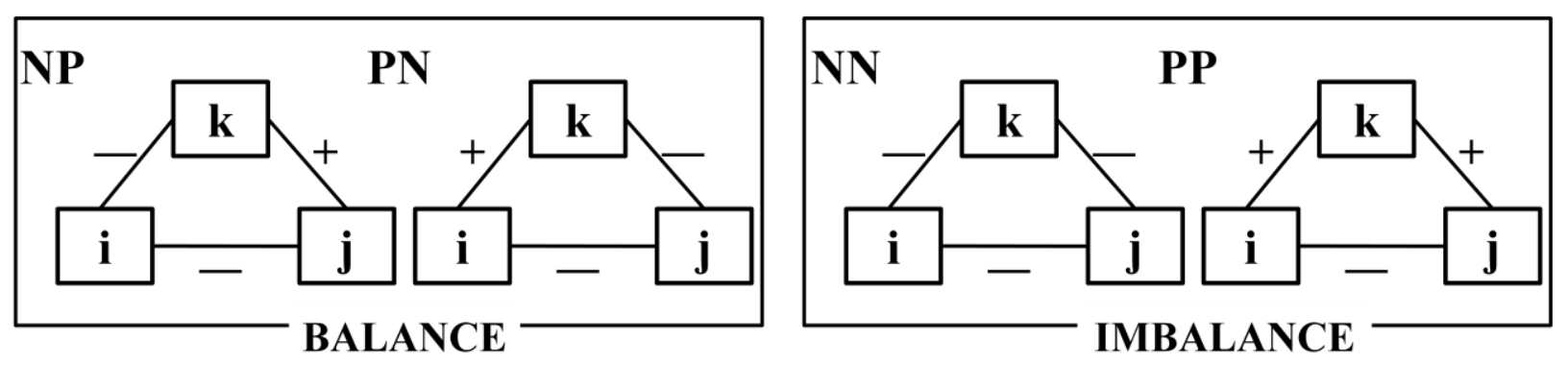

Figure 1. Four Possible Complete Triadic Configurations Where $<\mathrm{i}, \mathrm{j}>$ Pair is Negative 


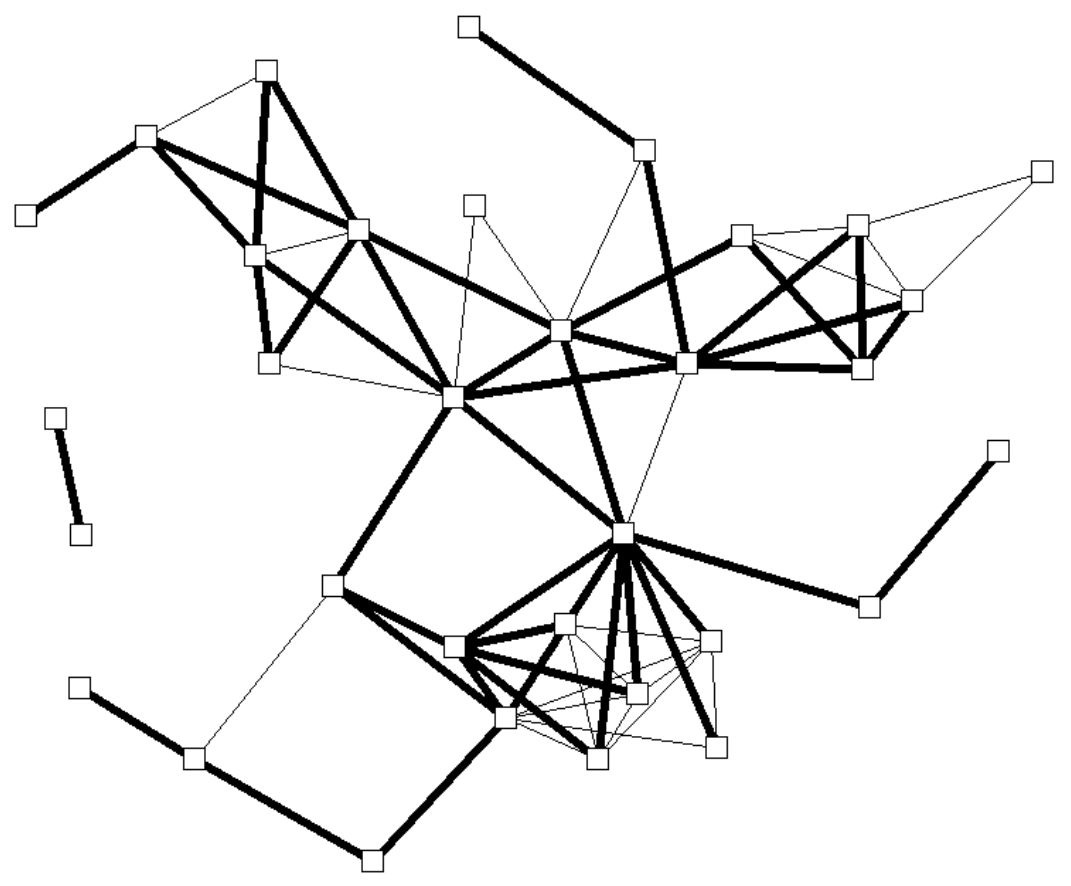

Figure 2. Gang Network

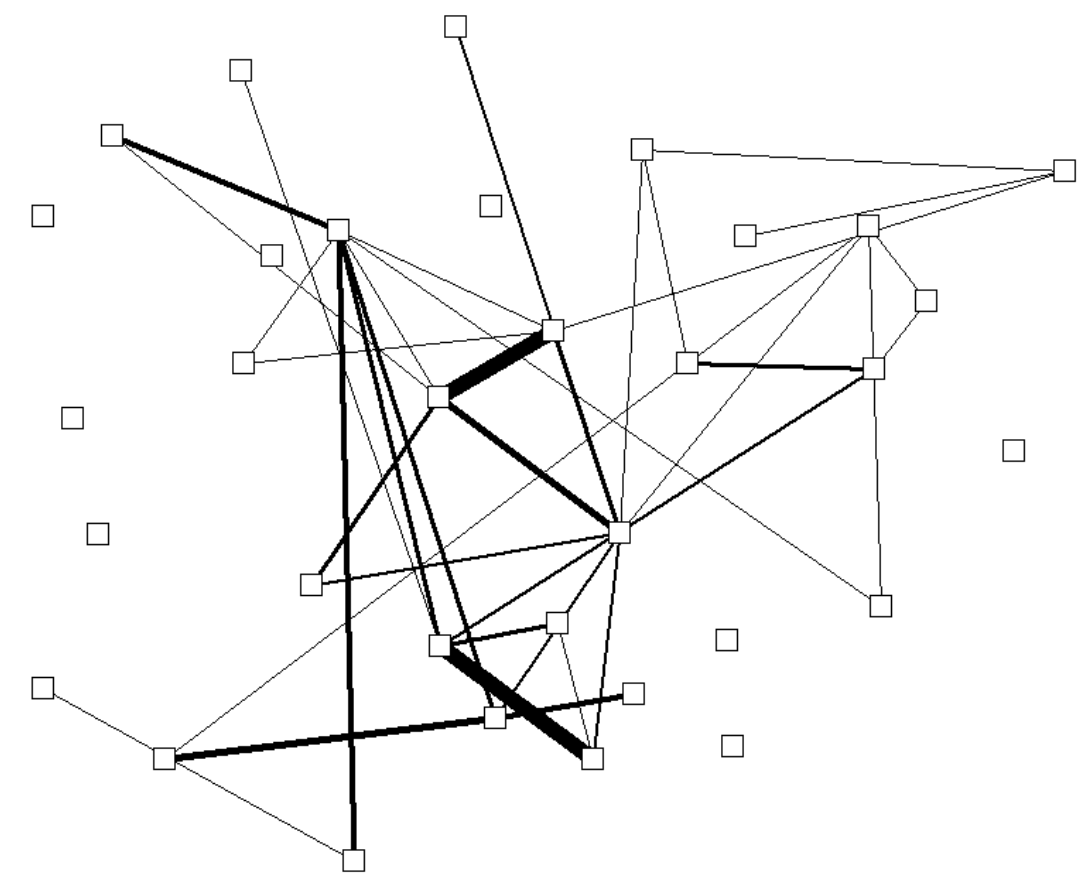

Figure 3. Gang Network with Violent Incidents 
Table 1: Means, Standard Deviations, and Correlations ${ }^{\mathrm{a}}$

\begin{tabular}{|c|c|c|c|c|c|c|c|c|c|c|c|c|c|c|c|c|c|c|c|c|c|}
\hline & Means & s.d. & 1 & 2 & 3 & 4 & $5 \mathbf{a}$ & $5 \mathbf{b}$ & $6 \mathbf{a}$ & $6 \mathrm{~b}$ & 7 & 8 & 9 & 10 & 11 & 12 & 13 & 14 & 15 & 16 & 17 \\
\hline 1. Incident & .07 & .55 & & & & & & & & & & & & & & & & & & & \\
\hline 2. O: Null & .91 & .29 & -.25 & & & & & & & & & & & & & & & & & & \\
\hline 3. P: Ally & .03 & .18 & .02 & -.58 & & & & & & & & & & & & & & & & & \\
\hline $\begin{array}{l}\text { 4. Size } \\
\text { Difference }\end{array}$ & .00 & 259.83 & .01 & .00 & .00 & & & & & & & & & & & & & & & & \\
\hline 5a. AED & 2.23 & 2.14 & .14 & -.21 & .03 & .41 & & & & & & & & & & & & & & & \\
\hline 5b. VED & 2.23 & 2.16 & .15 & -.21 & .03 & -.40 & -.03 & & & & & & & & & & & & & & \\
\hline 6a. AAD & 1.25 & 1.48 & .06 & -.16 & .22 & .02 & .15 & .00 & & & & & & & & & & & & & \\
\hline 6b. VAD & 1.25 & 1.48 & .02 & -.16 & .22 & -.02 & .00 & .14 & -.03 & & & & & & & & & & & & \\
\hline 7. \# Attacks & 8.98 & 14.74 & .19 & -.16 & .04 & .54 & .72 & -.02 & .17 & .00 & & & & & & & & & & & \\
\hline 8. \# Victimized & 11.40 & 18.32 & .17 & -.15 & .04 & -.52 & -.02 & .65 & .00 & .19 & -.02 & & & & & & & & & & \\
\hline 9. Adjacency & .06 & .23 & .18 & -.40 & .08 & .00 & .16 & .17 & .06 & .06 & .15 & .15 & & & & & & & & & \\
\hline 10. Ethnicity & .53 & .50 & .00 & -.04 & .17 & .00 & -.05 & -.05 & .12 & .12 & -.01 & .01 & -.03 & & & & & & & & \\
\hline 11. BALANCE & .09 & .49 & .19 & -.55 & -.03 & .00 & .21 & .21 & .08 & .08 & .13 & .10 & .32 & -.09 & & & & & & & \\
\hline $\begin{array}{l}12 . \\
\text { IMBALANCE }\end{array}$ & .04 & .27 & .46 & -.47 & -.03 & .00 & .22 & .22 & .04 & .04 & .18 & .18 & .33 & -.05 & .41 & & & & & & \\
\hline 13. NP & .04 & .33 & .06 & -.41 & -.02 & .11 & .27 & .05 & -.04 & .15 & .17 & .03 & .23 & -.07 & .74 & .30 & & & & & \\
\hline 14. PN & .04 & .33 & .22 & -.41 & -.02 & -.11 & .05 & .27 & .15 & -.04 & .03 & .13 & .23 & -.07 & .74 & .30 & .09 & & & & \\
\hline 15. NO & .11 & .64 & .27 & -.54 & -.03 & .12 & .34 & .12 & .01 & .05 & .27 & .14 & .29 & -.11 & .44 & .43 & .46 & .19 & & & \\
\hline 16. OP & .04 & .28 & .18 & -.46 & -.03 & -.06 & .12 & .16 & .00 & .12 & .08 & .19 & .26 & -.06 & .27 & .41 & .16 & .23 & .41 & & \\
\hline 17. PO & .04 & .28 & .21 & -.46 & -.03 & .06 & .17 & .13 & .12 & .00 & .18 & .07 & .26 & -.06 & .27 & .41 & .23 & .16 & .51 & .31 & \\
\hline 18. ON & .11 & .64 & .23 & -.54 & -.03 & -.11 & .13 & .34 & .05 & .01 & .13 & .22 & .29 & -.11 & .44 & .43 & .19 & .46 & .42 & .51 & .41 \\
\hline
\end{tabular}

${ }^{\mathrm{a}}$ Correlations in bold are significant at $p<.05$ (two-tailed).

Incident: Violent Gang Incident (Dependent Variable)

AED: Attacker Enemy Degree

VED: Victim Enemy Degree

AAD: Attacker Ally Degree

VAD: Victim Ally Degree

Adjacency: Geographical Adjacency

Ethnicity: Ethnicity Match 
Table 2: MRQAP Coefficients of Structural Variables and Controls from the Models Predicting the Number of Violent Attacks $(n=1560)$

\begin{tabular}{|c|c|c|c|c|c|c|}
\hline \multirow[b]{2}{*}{ Independent Variables } & \multicolumn{2}{|c|}{ Model 1} & \multicolumn{2}{|c|}{ Model 2} & \multicolumn{2}{|c|}{ Model 3} \\
\hline & Coef. & Sig. & Coef. & Sig. & Coef. & Sig. \\
\hline Intercept & .576 & - & .051 & - & .102 & - \\
\hline BALANCE: (NP, PN) & -.051 & .075 & - & - & -.038 & .112 \\
\hline IMBALANCE: (NN, PP) & - & - & .835 & .000 & .834 & .000 \\
\hline \multicolumn{7}{|l|}{ Controls } \\
\hline O: Null Relation & -.644 & .000 & -.072 & .147 & -.127 & .094 \\
\hline P: Ally Relation & -.612 & .000 & -.011 & .459 & -.068 & .259 \\
\hline Size Difference/100 & .005 & .203 & .005 & .215 & .005 & .216 \\
\hline Attacker Enemy Degree & -.011 & .028 & -.019 & .001 & -.019 & .004 \\
\hline Victim Enemy Degree & .004 & .267 & -.003 & .304 & -.002 & .336 \\
\hline Attacker Ally Degree & .012 & .036 & .009 & .106 & .010 & .088 \\
\hline Victim Ally Degree & -.007 & .170 & -.009 & .096 & -.009 & .125 \\
\hline \# Attacks & .006 & .000 & .005 & .000 & .005 & .000 \\
\hline \# Victimized & .004 & .001 & .004 & .001 & .004 & .001 \\
\hline Geographical Adjacency & .069 & .127 & -.002 & .517 & -.001 & .548 \\
\hline Ethnicity Match & .014 & .308 & .018 & .232 & .016 & .267 \\
\hline
\end{tabular}

Note: MRQAP tests are based on 2000 permutations. Sig (Significance) is equivalent to the $\mathrm{p}$ value calculated by the MRQAP test (two-tailed).

Dependent Variable is the number of violent attacks. 

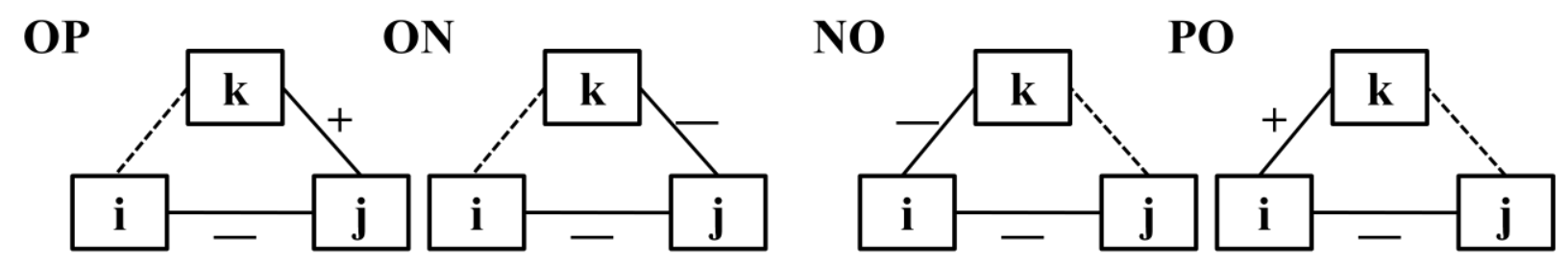

Figure 4. Four Possible Incomplete Triadic Configurations Where <i, $\mathbf{j}>$ Pair is Negative 
Table 3: MRQAP Coefficients of Structural Variables (BALANCE decomposed to NP and PN) and Controls from the Models Predicting the Number of Violent Attacks ( $n=1560)$

\begin{tabular}{|c|c|c|c|c|}
\hline \multirow[b]{2}{*}{ Independent Variables } & \multicolumn{2}{|c|}{ Model 4} & \multicolumn{2}{|c|}{ Model 5} \\
\hline & Coef. & Sig. & Coef. & Sig. \\
\hline Intercept & .102 & - & .037 & - \\
\hline $\mathbf{N P}$ (balanced) & -.193 & .002 & -.256 & .000 \\
\hline NO & - & - & .109 & .006 \\
\hline $\mathbf{O P}$ & - & - & -.107 & .024 \\
\hline PN (balanced) & .116 & .020 & .137 & .014 \\
\hline PO & - & - & -.036 & .164 \\
\hline ON & - & - & -.031 & .091 \\
\hline IMBALANCE (NN,PP) & .833 & .000 & .836 & .000 \\
\hline \multicolumn{5}{|l|}{ Controls } \\
\hline O: Null Relation & -.126 & .084 & -.087 & .182 \\
\hline P: Ally Relation & -.068 & .236 & -.033 & .372 \\
\hline Size Difference/100 & .006 & .128 & .004 & .221 \\
\hline Attacker Enemy Degree & -.013 & .025 & - & - \\
\hline Victim Enemy Degree & -.008 & .100 & - & - \\
\hline Attacker Ally Degree & .003 & .321 & - & - \\
\hline Victim Ally Degree & -.001 & .464 & - & - \\
\hline \# Attacks & .005 & .001 & .004 & .002 \\
\hline \# Victimized & .004 & .001 & .003 & .001 \\
\hline Geographical Adjacency & -.001 & .548 & .004 & .430 \\
\hline
\end{tabular}




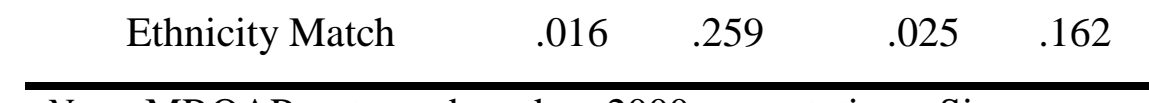

Note: MRQAP tests are based on 2000 permutations. Sig (Significance) is the $\mathrm{p}$ value calculated by the MRQAP test (two tailed).

Dependent Variable is the number of violent attacks. 